Pensamiento Crítico N. ${ }^{\circ}$ 13, pp. 23-42

\title{
Estructura de la industria manufacturera según el valor de ventas
}

\author{
Gilberto José Rafael Cárdenas Núñez ${ }^{1}$ \\ rafaelcardenasn@hotmail.com
}

\section{RESUMEN}

Luego de muchos años se realiza un Censo Económico en el Perú, con el efecto de volver a contar con información especializada sobre el sector económico productivo manufacturero. En el análisis realizado se aprecia que la estructura de producción manufacturera está especialmente orientada al mercado interno, y con mínimo desarrollo del sector de bienes de capital. Un sector manufacturero que ubica al Perú como productor de bienes manufactureros no transables a pesar que diversos gobiernos han suscrito varios Tratados de Libre Comercio con diversos países o grupos económicos del mundo. La manufactura peruana es simple y propia de países en extremo atrasados en la producción de bienes con cierto grado de desarrollo tecnológico.

Palabras clave: Censo, manufactura, Perú, estructura, TLC.

1 Economista, Maestro en Ciencias Planificación Nacional del Desarrollo, estudios concluidos de doctorado en Ciencias Contables y Empresariales, profesor principal e Investigador de la Facultad de Ciencias Económicas de la UNMSM. Actualmente director del Instituto de Estudios Económicos. 


\title{
Pensamiento Crítico N. 13
}

\begin{abstract}
After many years there is an economic census in Peru, with the effect of having again specialized information on the manufacturing productive economic sector. The analysis shows that the manufacturing structure is specially designed for the domestic market, and with minimal development of the capital goods sector. A manufacturing sector that put to Peru as a producer of non-tradable manufactured goods even though many governments have signed several FTAs with several countries or economic groups in the world. Peruvian manufacture sector in simple and typical of extremely backward countries in the production of goods with some degree of technological development.
\end{abstract}

Keywords: Census, manufacturing, Peru, structure, FTA.

\section{Introducción}

Para realizar el análisis de la actividad manufacturera peruana es necesario partir de la información del valor de las ventas a nivel de dos dígitos, o sea por grandes agrupaciones manufactureras y luego el detalle a nivel de cuatro dígitos, pues relieva con mayor especificación las actividades manufactureras con mayor participación en la economía peruana, en especial aquellas que tienen directa vinculación con actividades de mercado interno como es el caso de la refinería de petróleo, o ligadas a la exportación y a la vez al mercado interno como en el caso de pescado y productos de pescado, hilados y tejidos, prendas de vestir, productos de plástico, fundición de metales no ferrosos, principalmente.

Es importante señalar que por razones de brevedad se resume en el título de cada actividad, sea a nivel de dos dígitos o de cuatro de la Clasificación Industrial Internacional Uniforme, aunque en el gráfico y el análisis se mencionan específicamente cada una de las actividades que comprende las grandes agrupaciones a nivel de dos dígitos. El valor de las ventas está en millones de nuevos soles del 2006, año en el que se realizó el Censo Económico Nacional. 


\section{Gilberto José Rafael Cárdenas Núñez}

Cuadro 1. Valor de ventas o transferencias de establecimientos o empresas manufactureras según división CIIU año 2006 (Millones de nuevos soles corrientes del 2006).

\begin{tabular}{|c|l|c|}
\hline CIIU & \multicolumn{1}{|c|}{ Total manufacturero } & $\mathbf{7 1 ~ 1 5 1 , 6}$ \\
\hline 15 & Alimentos y bebidas & 20207,6 \\
\hline 16 & Tabaco & 2,5 \\
\hline 17 & Hilados y textiles & 3942,4 \\
\hline 18 & Prendas de vestir & 2965,3 \\
\hline 19 & Productos de cuero & 343,4 \\
\hline 20 & Productos de madera & 652,9 \\
\hline 21 & Productos de papel y derivados & 1103,9 \\
\hline 22 & Impresos & 1352,9 \\
\hline 23 & Carbón y petróleo & 14784,9 \\
\hline 24 & Industria química & 5136,5 \\
\hline 25 & Productos de caucho y plástico & 3503,2 \\
\hline 26 & Productos de vidrio y cemento & 3406 \\
\hline 27 & Hierro y acero & 8912,1 \\
\hline 28 & Productos metálicos & 1542,4 \\
\hline 29 & Maquinaria y equipo & 667,4 \\
\hline 30 & Equipos de oficina & 50,1 \\
\hline 31 & Motores eléctricos y otros & 1141,9 \\
\hline 32 & Radio y televisión & 1 \\
\hline 33 & Equipos médicos y de medición & 29,9 \\
\hline 34 & Automotores y otros & 265,5 \\
\hline 35 & Material de transporte & 196 \\
\hline 36 & Muebles y otros & \\
\hline 37 & Reciclados & 28,2 \\
\hline & & \\
\hline
\end{tabular}

Fuente: INEI, Censo Nacional Manufacturero 2006.

Como se puede apreciar en el cuadro anterior, la producción de alimentos y bebidas representa el $28,4 \%$ de la producción manufacturera nacional, seguida de carbón y petróleo con $20,78 \%$ y hierro y acero con $12,53 \%$. Los productos industriales 


\section{Pensamiento Crítico N. I3}

peruanos de mayor significación son, en consecuencia, bienes de consumo fungible el primero y el segundo y tercero, bienes intermedios.

Gráfico 1. Estructura de la manufactura peruana año 2006 (Millones de nuevos soles corrientes del 2006).

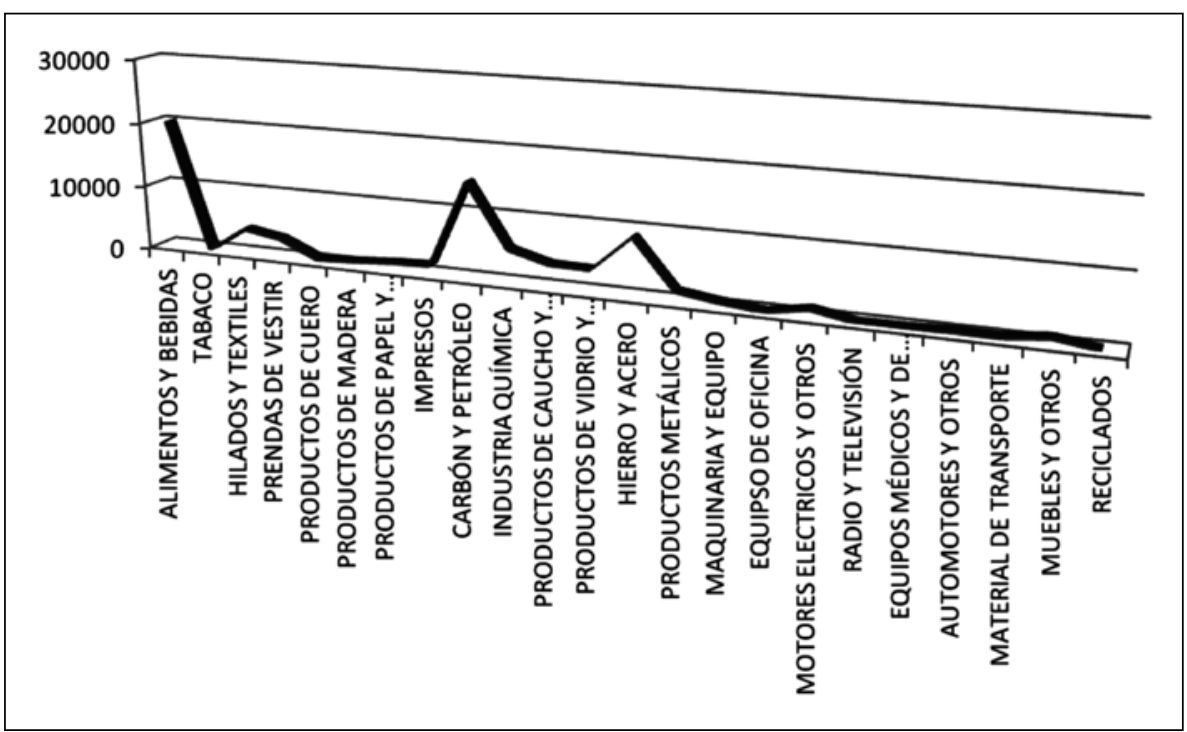

Fuente: Cuadro N. ${ }^{\circ} 1$.

Elaboración: el autor.

\section{Las actividades manufactureras a nivel de dos dígitos}

\section{Elaboración de productos alimenticios y bebidas}

En el caso de alimentos y bebidas, que representa cerca del $30 \%$ del valor anotado por el Censo Nacional Manufacturero, las actividades de productos de pescado, grasas y lácteos, así como malteadas representan los principales valores sobre el total de la actividad. Es notable la participación de los productos de pescado en este rubro. 


\section{Gilberto José Rafael Cárdenas Núñez}

Se puede apreciar que las empresas y establecimientos de manufacturas con mayor capacidad generadora de valor están directamente vinculadas a un recurso natural agotable que es la pesca. En tal sentido, la preservación del recurso se constituye en política fundamental para hacer sostenible la actividad industrial manufacturera, así como que se pueda abrir la posibilidad de generar otros productos, en especial con la perspectiva del mercado internacional.

Gráfico 2. Alimentos y bebidas

(Millones de nuevos soles corrientes del 2006).

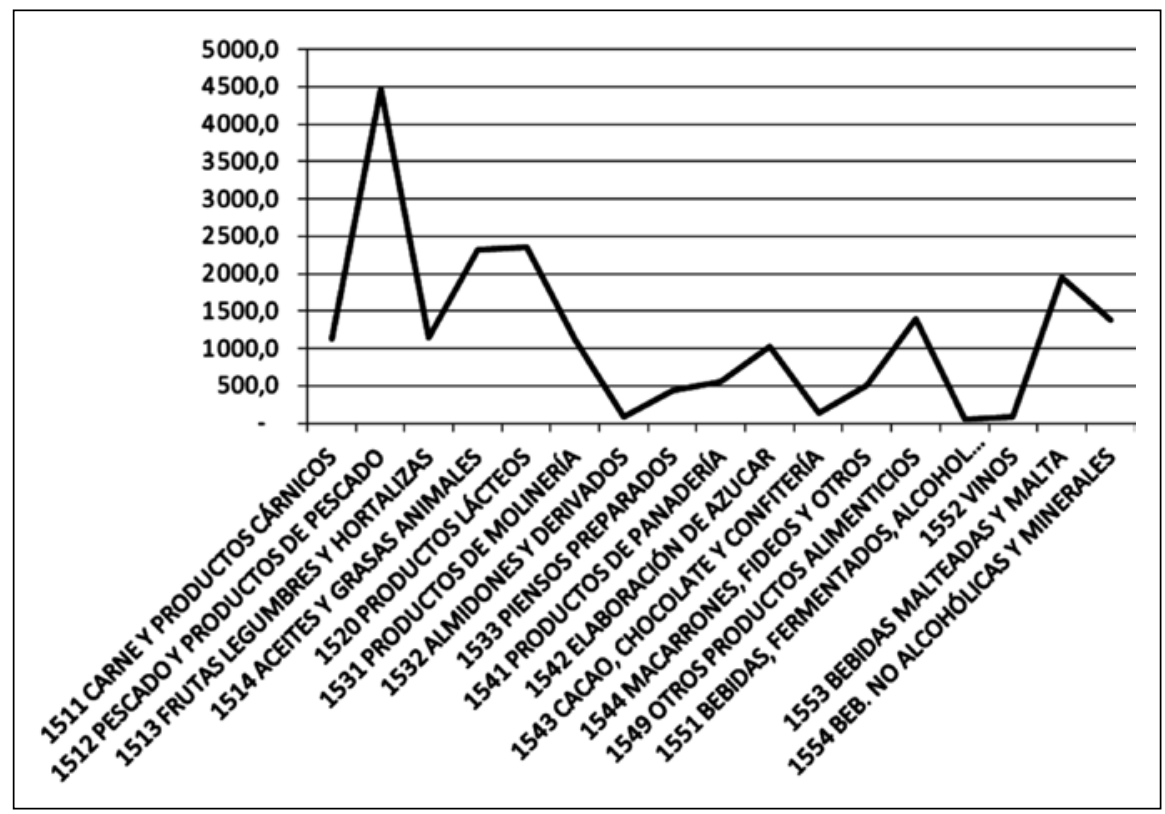

Fuente: INEI, Censo Nacional Manufacturero 2006.

Elaboración: el autor.

En el Gráfico de la actividad de alimentos y bebidas, se puede apreciar con nitidez la especial importancia de la actividad de transformación del recurso pesca, apreciándose también la importancia de las actividades de aceites y grasas, así como la de productos lácteos y bebidas malteadas. 


\section{Pensamiento Crítico N. ${ }^{\circ}$ I3}

En éstos últimos tres casos mencionados, las tres actividades se sustentan fundamentalmente en insumos importados; en consecuencia, aparte de la importancia del mercado interno sobre estas tres actividades, la vulnerabilidad que presentan se centra en la volatilidad del mercado internacional que puede hacer escasear el producto y en consecuencia elevar los precios internacionales. La política cambiaria del país puede de alguna manera mediatizar dicha volatilidad y así garantizar la manutención del mercado interno como factor determinante de la cantidad demandada en dichas actividades.

Las otras actividades tienen menor importancia en el valor generado, y en consecuencia su influencia en el mercado interno es mucho menor.

\section{Fabricación de productos textiles}

Actividad manufacturera que desarrolla importantes avances tecnológicos cuando se exporta hacia los Estados Unidos. Gran problema para su sostenimiento es que no diversificó mercados con lo cual se vio fuertemente afectada con la gran crisis internacional generada en los Estados Unidos, principal mercado externo, a partir del 2008.

Gráfico 3. Textiles

(Millones de nuevos soles corrientes del 2006)

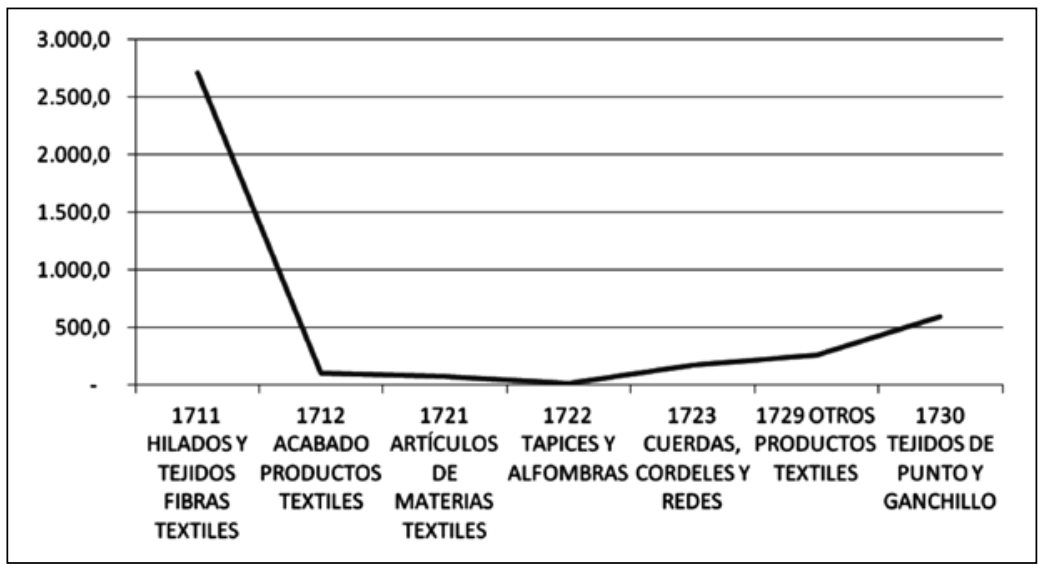

Fuente: INEI, Censo Nacional Manufacturero 2006.

Elaboración: el autor. 


\section{Gilberto José Rafael Cárdenas Núñez}

En la actividad de textiles, los hilados y tejidos son los principales productos de esta industria manufacturera, constituyendo la producción de insumos para los bienes finales, lo que se desarrolla con fuerza. Los hilados y textiles son utilizados por otras actividades productivas, como se analizará posteriormente.

\section{Fabricación de prendas de vestir; adobo y teñido de pieles}

En esta actividad predomina la producción de prendas de vestir, la gran mayoría de la producción es para el mercado interno aunque se han logrado pequeñas cuotas en mercados externos, en especial en los Estados Unidos y en Venezuela.

Gráfico 4. Prendas de vestir

(Millones de nuevos soles corrientes del 2006)

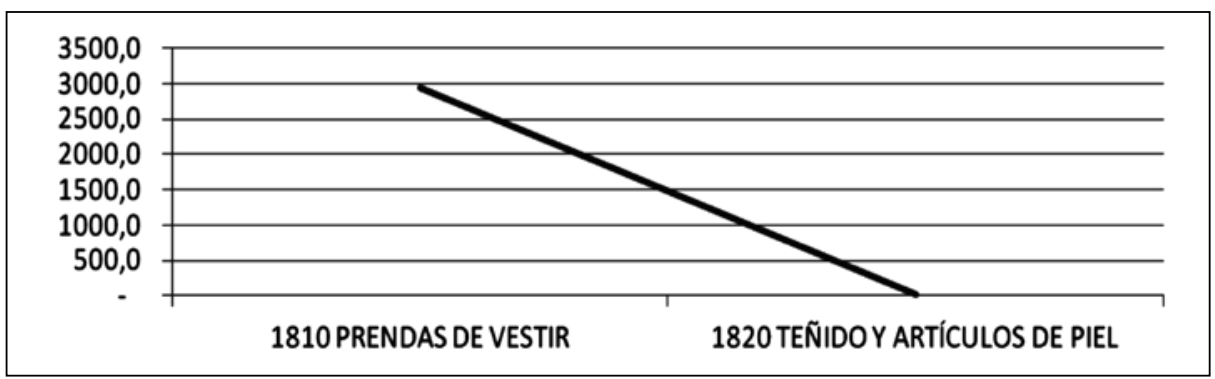

Fuente: INEI, Censo Nacional Manufacturero 2006.

Elaboración: el autor.

En lo relativo a la actividad de prendas de vestir, la utilización de los insumos nacionales provenientes de la actividad de hilados y textiles, para la producción de bienes de consumo final como son las prendas de vestir, parte de los cuales tienen importante mercado en el exterior.

La producción de artículos de piel no tiene importancia significativa en la industria manufacturera de 10 a más trabajadores. 


\section{Curtido y adobo de cueros; fabricación de maletas, bolsos de mano, artículos de talabartería, guarnición, y calzado}

En la actividad industrial manufacturera de productos de cuero, la producción de calzado es la más importante. El insumo principal es en parte nacional pero que no cubre la demanda de la actividad a nivel nacional, lo cual obliga a importar crecientemente el faltante de este insumo, principalmente la piel de ganado vacuno. Esta actividad tiene como principal elemento dinamizador en el mercado interno, el que es un bien básico para la población.

Gráfico 5. Productos de cuero

(Millones de nuevos soles corrientes del 2006)

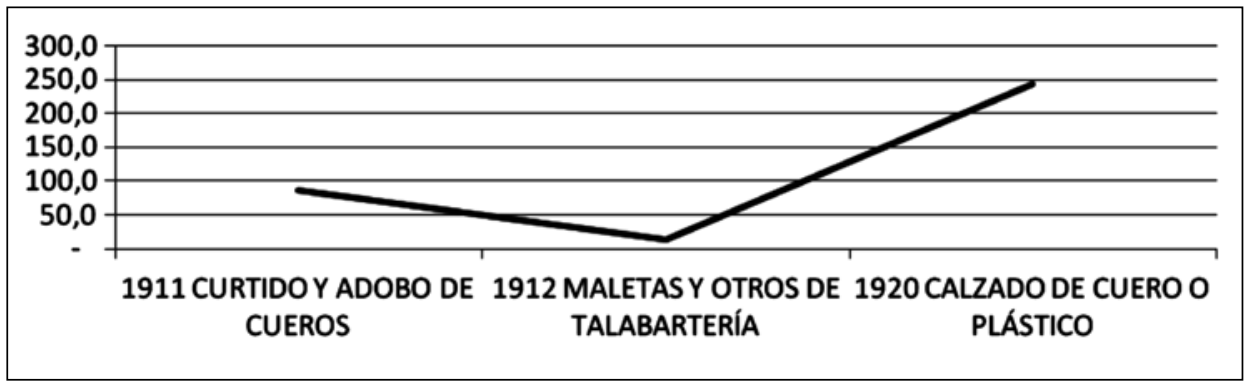

Fuente: INEI, Censo Nacional Manufacturero 2006.

Elaboración: el autor.

\section{Producción de madera y fabricación de productos de madera y corcho, ex- cepto muebles; fabricación de artículos de paja y de materiales trenzables}

En la actividad de productos de madera, el aserrado y cepillado de madera son los más importantes, y está basada en el recurso nacional que es la madera de la selva del país. La actividad de los aserraderos como principal actividad, da pie a la utilización de derivados de la misma para hacer tableros de madera, importante producto que constituye un insumo para la industria de construcción, sea en la construcción de viviendas como en la construcción de edificios comerciales. 


\section{Gilberto José Rafael Cárdenas Núñez}

Gráfico 6. Productos de madera

(Millones de nuevos soles corrientes del 2006)

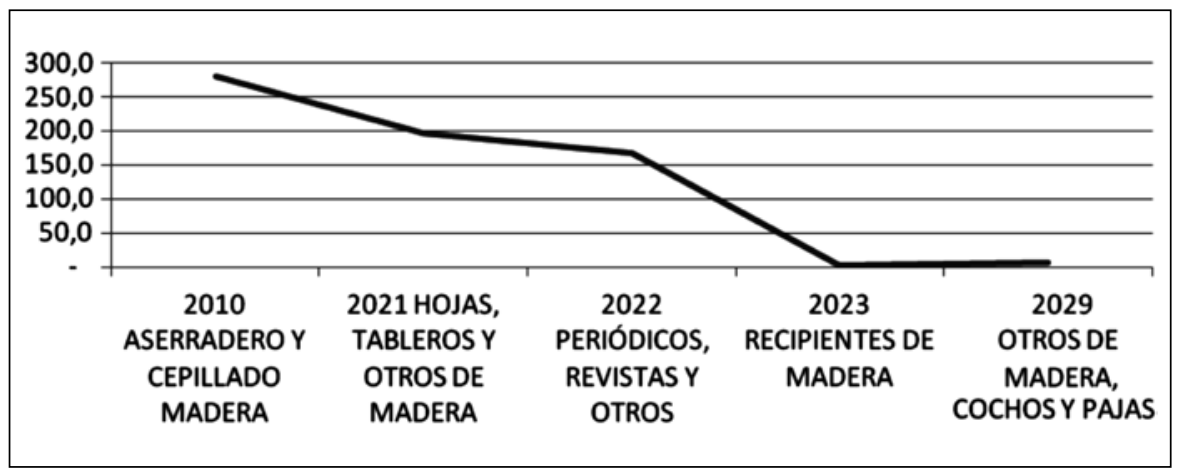

Fuente: INEI, Censo Nacional Manufacturero 2006.

Elaboración: el autor.

\section{Fabricación de papel y productos de papel}

En cuanto a la producción de papel y derivados, la actividad principal en el país es de otros productos de papel como cartón y envases de papel. Esta relativa importancia de la mencionada actividad se debe a la industria de impresos y otros, así como a la utilización de envases para la actividad de comercio.

Es necesario tener en cuenta que además de la producción nacional, también hay una importante magnitud de importaciones de papel, en especial de Chile y de los Estados Unidos.

Es necesario anotar que el desarrollo de la democracia y de la libertad de prensa impactan en forma notable en la producción de diarios y otros impresos. 


\section{Pensamiento Crítico N. 13}

Gráfico 7. Productos de papel y derivados

(Millones de nuevos soles corrientes del 2006)

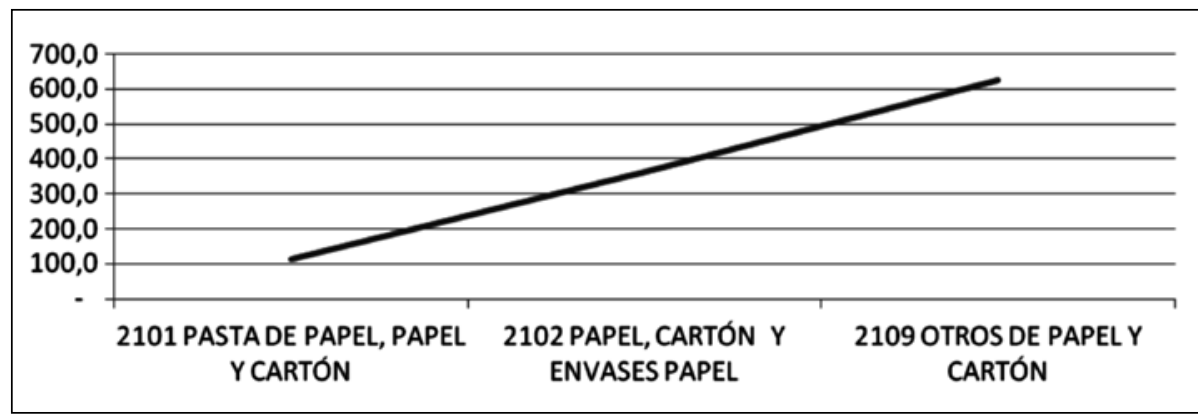

Fuente: INEI, Censo Nacional Manufacturero 2006.

Elaboración: el autor.

\section{Fabricación de sustancias y productos químicos}

En la industria de productos químicos y derivados sobresale la producción de productos farmacéuticos, jabones y detergentes así como la de sustancias químicas. Las dos primeras actividades mencionadas están estrechamente ligadas a la satisfacción de las necesidades de salud y de aseo. Nuevamente se percibe la importancia de la demanda interna proveniente de la población como demandante final para la industria manufacturera nacional.

Por otro lado, la actividad también importante, pero que es básicamente de productos intermedios o que sirven como insumos para otras actividades manufactureras, es la actividad de producción de sustancias químicas. Estas sustancias son utilizadas para diversos fines en la propia industria de actividades químicas, como en las industrias de alimentos, bebidas, textiles y otras. 


\section{Gilberto José Rafael Cárdenas Núñez}

Gráfico 8. Industria química

(Millones de nuevos soles corrientes del 2006)

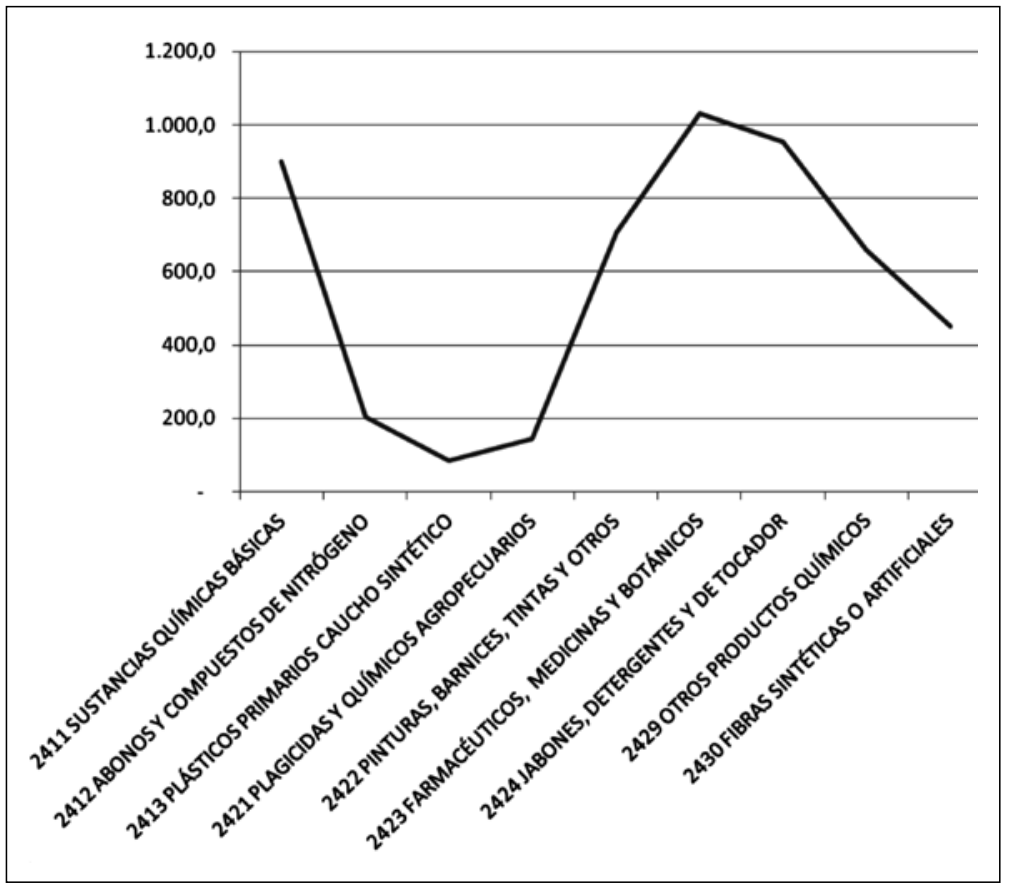

Fuente: INEI, Censo Nacional Manufacturero 2006.

Elaboración: el autor.

\section{Fabricación de otros productos minerales no metálicos}

En cuanto a la actividad manufacturera de vidrio, cerámica y cemento, sobresale la producción nacional de cemento, cal y yeso. El cemento es el principal producto y tiene especial significado, pues se basa en un insumo nacional que deriva de la industria minera de productos de canteras, en especial de la caliza, aunque otros para la cal y yeso.

Pero además, el cemento derivado de la caliza, sigue el proceso productivo y constituye el material principal, junto al ladrillo, para la construcción de viviendas 


\section{Pensamiento Crítico N. ${ }^{\circ}$ I3}

y edificios comerciales, actividad de especial importancia en cuanto a inversión económica.

La política económica en el país ha dado especial importancia a esta actividad pues además de generar una dinámica relación insumo producto sustentada en insumo nacional, que la hace en buena parte sustentable, la lleva a cabo con ingeniería peruana, aunque la maquinaria es importada.

El resto de actividades manufactureras de 10 a más trabajadores no es relevante para la economía nacional, pues es de poca magnitud económica.

Gráfico 9. Productos de vidrio y cemento

(Millones de nuevos soles corrientes del 2006)

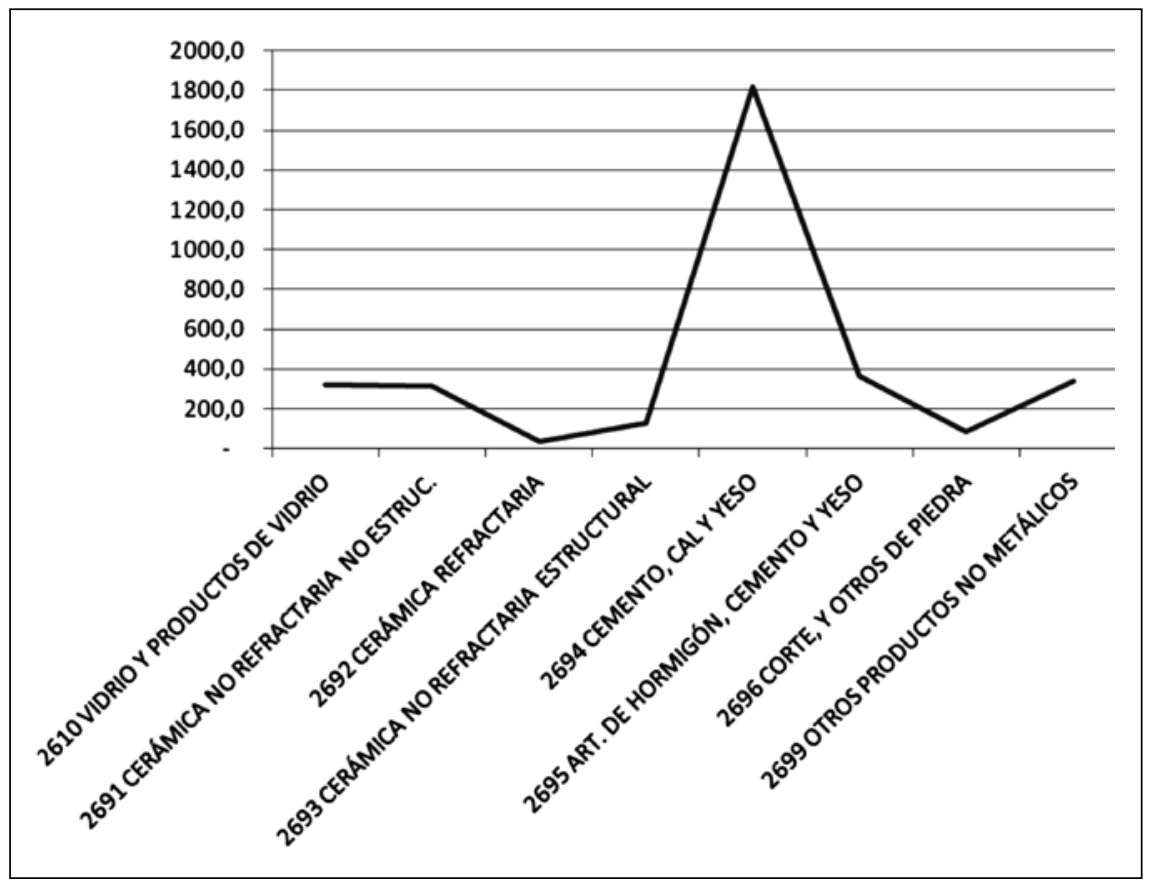

Fuente: INEI, Censo Nacional Manufacturero 2006.

Elaboración: el autor. 


\section{Gilberto José Rafael Cárdenas Núñez}

\section{Fabricación de productos de caucho y plástico}

Y en cuanto a la producción de productos de plástico y caucho, lo principal es la de productos de plástico. Los productos de plástico son para la actividad doméstica principalmente, aunque también se utilizan para la actividad comercial pero en mucha menor medida. También los productos de esta actividad están estrechamente vinculados al mercado interno por efecto de la demanda de las familias.

Gráfico 10. Productos de caucho y plástico

(Millones de nuevos soles corrientes del 2006)

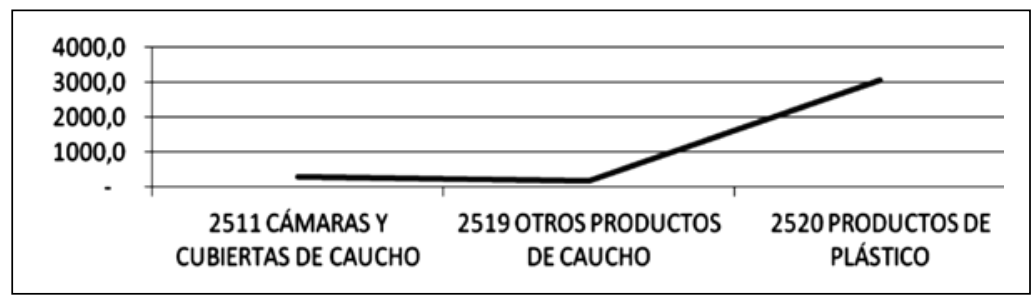

Fuente: INEI, Censo Nacional Manufacturero 2006.

Elaboración: el autor.

\section{Fabricación de metales comunes}

Es lo referente a la fundición de hierro para la producción de acero, pero sobresale la producción de fundición de metales no ferrosos, en especial el cobre.

Gráfico 11. Hierro y acero

(Millones de nuevos soles corrientes del 2006)

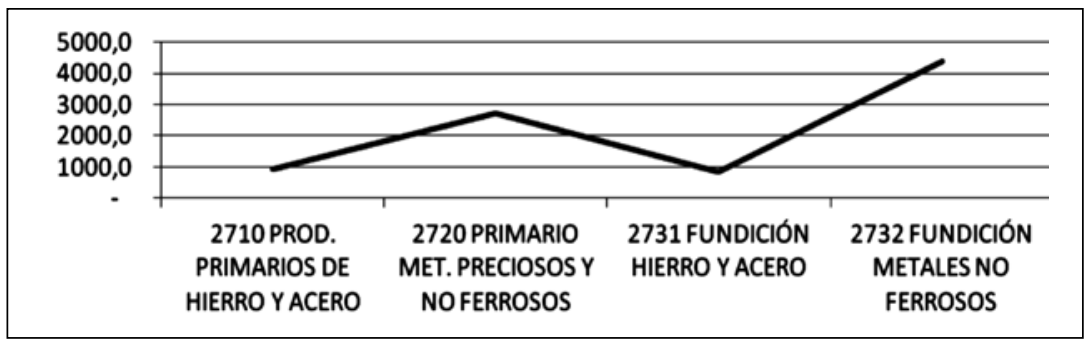

Fuente: INEI, Censo Nacional Manufacturero 2006.

Elaboración: el autor. 


\section{Pensamiento Crítico N. 13}

\section{Fabricación de productos elaborados de metal, excepto maquinaria y equipo}

En la industria de productos metálicos, lo más importante es la actividad de otros productos metálicos, en donde se encuentra multitud de derivados de acero y de otros metales. Pero en cuanto a una actividad específica, resalta la producción de metálicos para uso estructural. Esto se refiere también a la industria de construcción; lo importante es que se sustenta en insumos nacionales, y vende a la producción nacional de viviendas, el comercio mayorista y minorista, y edificaciones.

Gráfico 12. Productos metálicos

(Millones de nuevos soles corrientes del 2006)

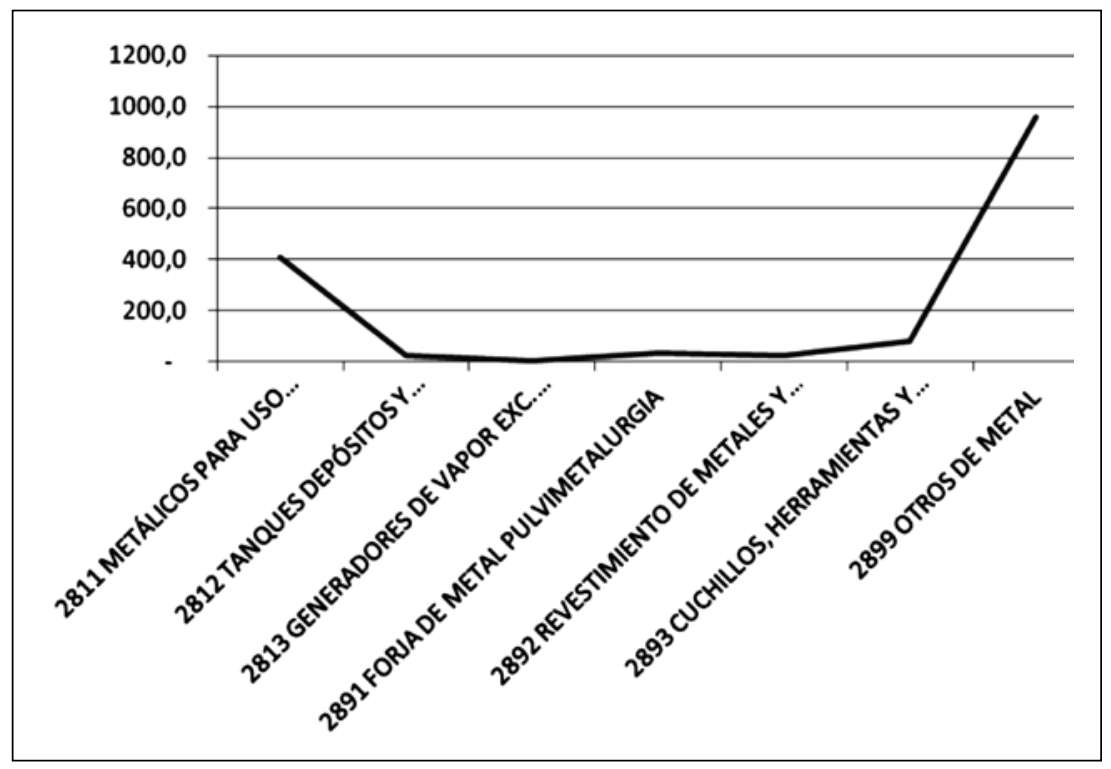

Fuente: INEI, Censo Nacional Manufacturero 2006.

Elaboración: el autor.

\section{Fabricación de maquinaria y equipo}

En lo referente a la actividad productora de maquinaria y equipo, el primer lugar en la generación de valor de ventas es para el rubro de otras maquinarias y equipos, pero la más importante en forma específica es la actividad productora de equipos 


\section{Gilberto José Rafael Cárdenas Núñez}

para la minería, característica propia de un país en el que la minería es una actividad fundamental para las exportaciones y generación de divisas. Se aprecia así una relación de la industria al servicio de la minería, como proveedora de equipos principalmente. Es importante también notar que el segundo lugar lo tiene la producción de maquinarias para minas y canteras, propio de la actividad cementera principalmente.

Gráfico 13. Maquinaria y equipo

(Millones de nuevos soles corrientes del 2006)

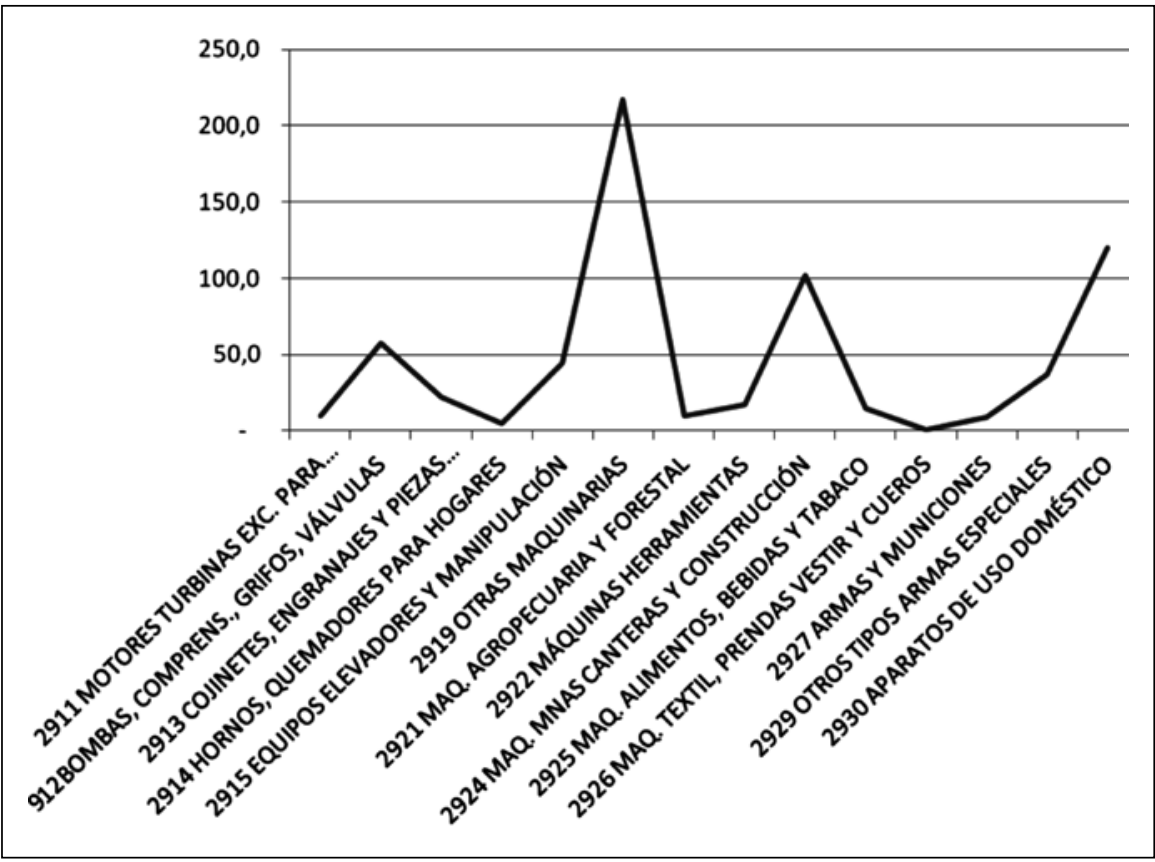

Fuente: INEI, Censo Nacional Manufacturero 2006.

Elaboración: el autor.

\section{Fabricación de maquinaria y aparatos eléctricos}

En la actividad productora de motores eléctricos y otros, sobresale la actividad de hilos y cables eléctricos, productos derivados de la industria minera del cobre, o sea, fundición no ferrosa. Los hilos y cables aislados son un insumo de la industria 


\section{Pensamiento Crítico N. I3}

de construcción de viviendas y edificios, que permite la estructuración del sistema eléctrico en domicilios. También es importante la producción de cables aislados para la conducción de electricidad de alta tensión.

Gráfico 14. Motores eléctricos y otros

(Millones de nuevos soles corrientes del 2006)

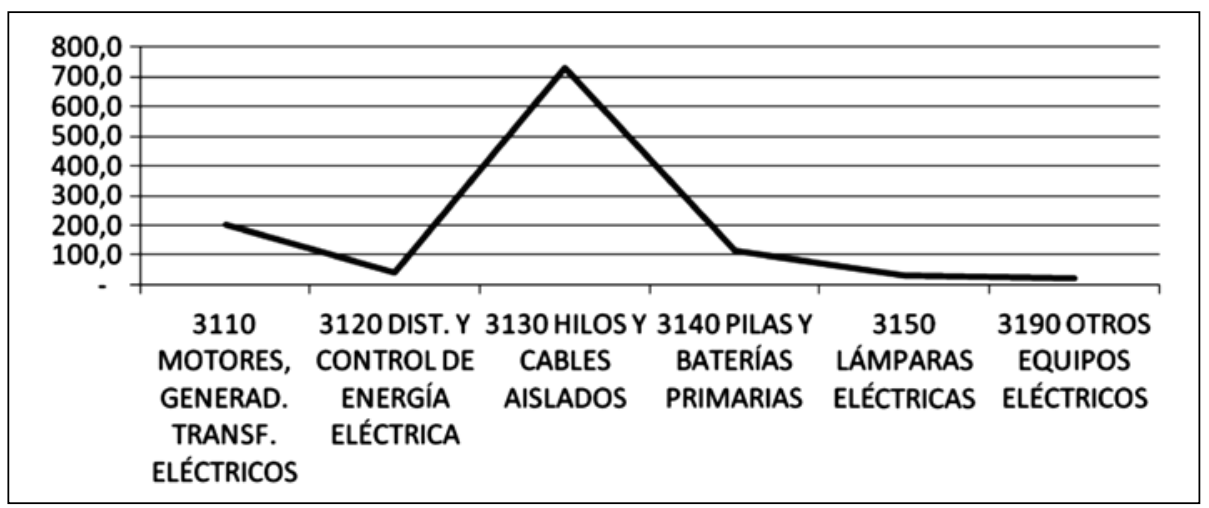

Fuente: INEI, Censo Nacional Manufacturero 2006.

Elaboración: el autor.

\section{Fabricación de equipos y aparatos de radio, televisión y comunicaciones}

En cuanto a la actividad de producción de productos de radio y televisión, tales actividades son de mínima importancia, pues es mínima la producción al respecto.

Cabe anotar que el desarrollo mínimo de esta actividad significa que la industria electrónica, sustancial en las economías desarrolladas, no se ha desarrollado en forma significativa en el país, en todo caso son algunas actividades de ensamblaje y reparación. 
Gráfico 15. Radio y televisión

(Millones de nuevos soles corrientes del 2006)

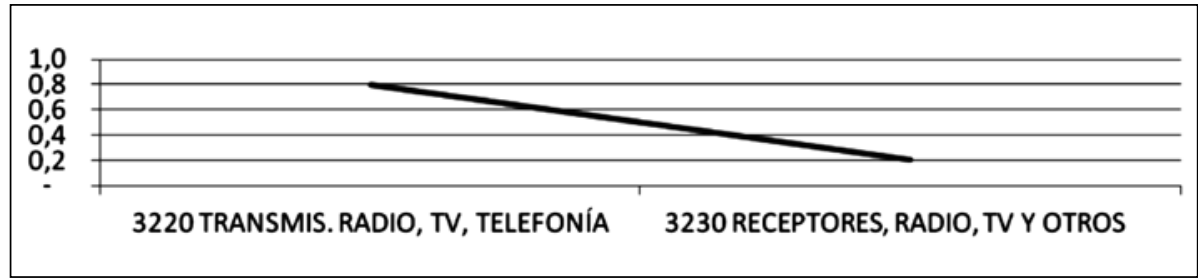

Fuente: INEI, Censo Nacional Manufacturero 2006.

Elaboración: el autor.

\section{Fabricación de instrumentos médicos, ópticos y de precisión y fabricación de relojes}

En cuanto a equipos de medición y médicos, los equipos quirúrgicos y de óptica son los resaltantes, y tienen como destino el sistema público de salud en el país, constituido por postas y hospitales en todo el país.

Gráfico 16. Equipos médicos y de medición

(Millones de nuevos soles corrientes del 2006)

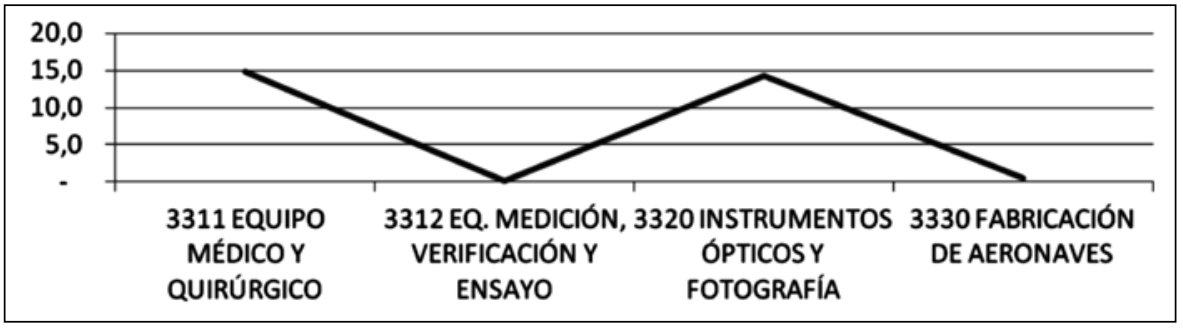

Fuente: INEI, Censo Nacional Manufacturero 2006.

Elaboración: el autor.

\section{Fabricación de vehículos automotores, remolques y semirremolques}

Pero no sólo en la actividad electrónica la industria manufacturera está muy atrasada y es poco representativa, sino también en la actividad de producción de automotores y otros, pues a lo más la industria manufacturera llega a elaborar partes y piezas para automotores, tanto para automóviles como para motos y otros similares, como actividad principal. 


\section{Pensamiento Crítico N. 13}

Gráfico 17. Automotores y otros

(Millones de nuevos soles corrientes del 2006)

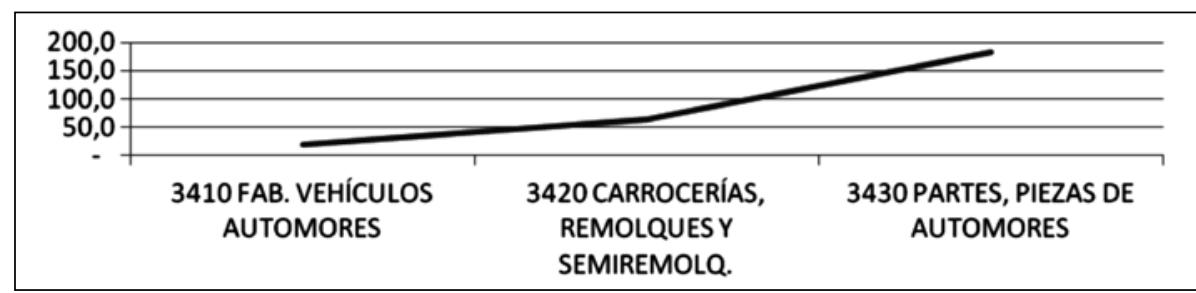

Fuente: INEI, Censo Nacional Manufacturero 2006.

Elaboración: el autor.

\section{Fabricación de otros tipos de materiales de transporte}

En cuanto a la construcción de otro tipo de embarcaciones y transportes, la producción y reparación de buques salta a la vista como actividad importante, en donde se encuentra el SIMA y las fábricas de bolicheras y naves de pesca.

Gráfico 18. Material de transporte

(Millones de nuevos soles corrientes del 2006)

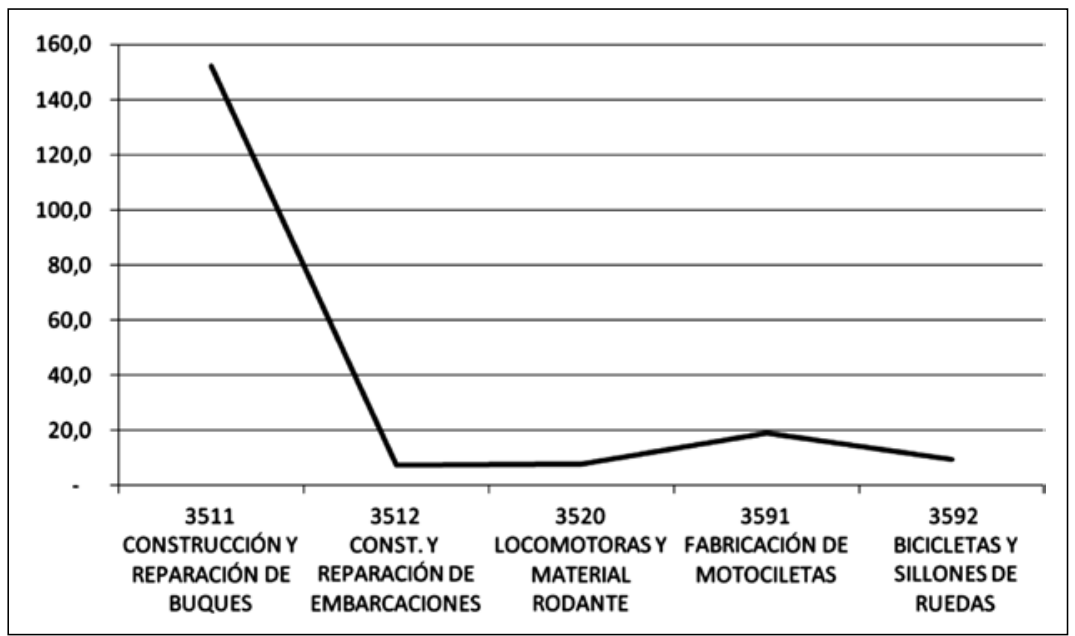

Fuente: INEI, Censo Nacional Manufacturero 2006.

Elaboración: el autor. 


\section{Gilberto José Rafael Cárdenas Núñez}

\section{Fabricación de muebles y de otras industrias manufactureras}

En lo referente a muebles, joyas y otros, la fabricación de muebles es lo más importante, vinculada a la construcción de viviendas, pues en la medida que se expande la oferta de inmuebles para vivienda, aumenta la producción de muebles para las mismas.

Gráfico 19. Muebles y otros

(Millones de nuevos soles corrientes del 2006)

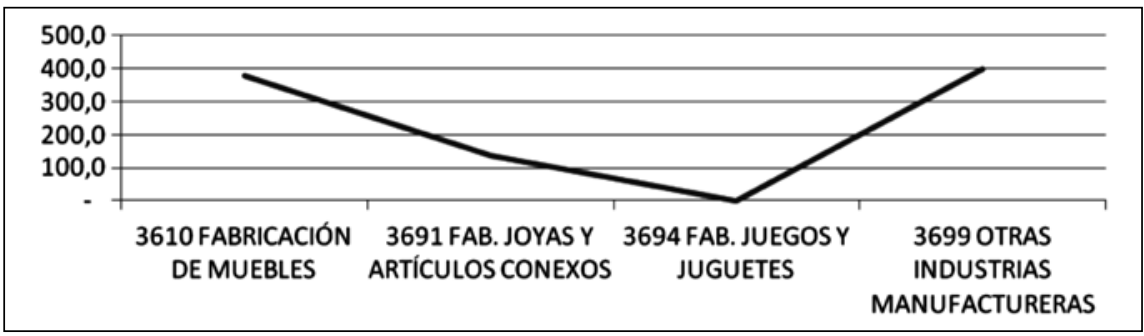

Fuente: INEI, Censo Nacional Manufacturero 2006.

Elaboración: el autor.

\section{Reciclamiento}

Por otro lado, la actividad de reciclado se centra principalmente en reciclado de desperdicios no metálicos.

Gráfica 20. Reciclados

(Millones de nuevos soles corrientes del 2006)

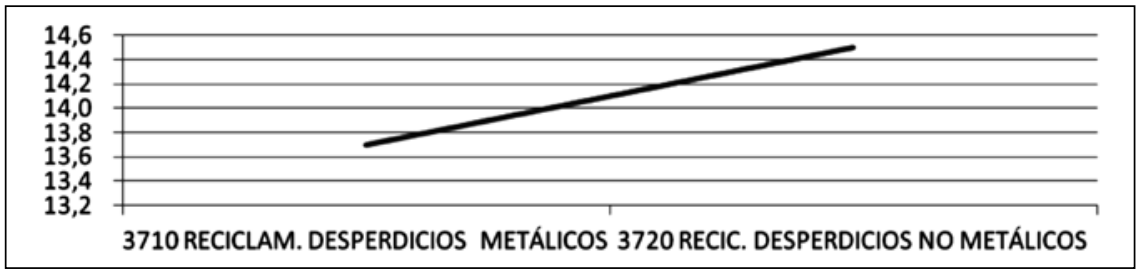

Fuente: INEI, Censo Nacional Manufacturero 2006.

Elaboración: el autor. 


\section{Pensamiento Crítico N. 13}

\section{Conclusiones}

1. La industria manufacturera peruana pierde presencia en el Producto Bruto Industrial peruano, debido a la imposibilidad de competir con la producción de otros países, inclusive con aquellos con los cuales se ha suscrito tratados de libre comercio.

2. La manifestación más evidente es que la producción es fundamentalmente de bienes no transables, como alimentos y bebidas, derivados de refinación de petróleo, cemento y otros no competitivos a nivel internacional.

3. El atraso del nivel tecnológico es evidente en la producción manufacturera nacional. La política de los sucesivos gobiernos ha sido contraproducente en la creación de ventajas competitivas.

\section{Fuente de consulta}

INEI, Censo Económico Nacional 2006, Actividad Manufacturera. 